\title{
Reconciling Landscape Fragmentation and Hippopotamuses Population Decrease in Virunga National Park Wetland
}

\author{
Madeleine Udahogora1,2, Zhaoping Yang1,2*, Patient Mindje ${ }^{1,2}$, Lamek Nahayo3, \\ Richard Mindje ${ }^{1,2}$, Vincent Nzabarinda ${ }^{1,2}$, Anathalie Nyirarwasa ${ }^{1,2}$ \\ ${ }^{1}$ State Key Laboratory of Desert and Oasis Ecology, Xinjiang Institute of Ecology and Geography, Chinese Academy of Sciences, \\ Urumqi, China \\ ${ }^{2}$ University of Chinese Academy of Sciences, Beijing, China \\ ${ }^{3}$ Faculty of Environmental Studies, University of Lay Adventists of Kigali, Kigali, Rwanda \\ Email: *yangzp@ms.xjb.ac.cn
}

How to cite this paper: Udahogora, M., Yang, Z. P., Mindje, P., Nahayo, L., Mindje, R., Nzabarinda, V., \& Nyirarwasa, A. (2020). Reconciling Landscape Fragmentation and Hippopotamuses Population Decrease in Virunga National Park Wetland. Journal of Geoscience and Environment Protection, 8, 63-76.

https://doi.org/10.4236/gep.2020.812004

Received: November 12, 2020

Accepted: December 11, 2020

Published: December 14, 2020

Copyright $\odot 2020$ by author(s) and Scientific Research Publishing Inc. This work is licensed under the Creative Commons Attribution International License (CC BY 4.0).

http://creativecommons.org/licenses/by/4.0/ (c) (i) Open Access

\begin{abstract}
Wetlands have been noted to be beneficial worldwide. Despite wetlands being a natural asset that is of great significance to the human community, they are threatened by human and natural events. In Virunga National Park (VNP) wetlands are the habitat of Hippopotamus (Hippopotamus amphibius) which are among the animal species threatened by extinction in VNP since the past few decades. As shown by the last studies the number of Hippos population declined for $96 \%$ for the period of less than 40 years. This study evaluated landscape fragmentation status and its implication on the decline of the hippos population in VNP wetland for the period from 1990 to 2018. This study's land cover data was obtained using remote sensing techniques with the help of software package ERDAS IMAGINE v16.6 and ArcGIS v10.3. It was mapped and classified using the maximum likelihood supervised classification technique. The landscape was classified into seven classes, which included Cropland, Forest, grassland, wetland, scrubland, bare area, and water. Satellite data (Landsat) was used to evaluate NDVI and NDWI and finally the landscape patterns in the study were analyzed using Fragstats 4.2 , which was also used to calculate landscape indices for the respective periods. The results obtained from the LULC, NDVI, NDWI and the landscape metrics showed that during the period of our study the VNP wetland was fragmented. A strong negative correlation between the number of hippos and the wetland's LFI (Landscape Fragmentation Index) values showed that wetland fragmentation was one of the reasons of the decline of Hippos in the park.
\end{abstract}




\section{Keywords}

Remote Sensing, Landscape Metrics, Virunga National Park, Hippopotamus

\section{Introduction}

According to a report published by Assessment (2005), wetlands have been noted to be beneficial worldwide, and their advantages include but not limited to mitigating erosion and purifying water. Despite wetlands being a natural asset that is of great significance to the human community, they are threatened by human and natural events (Blankespoor et al., 2014). Over the last century, wetlands worldwide have reduced by half, which can be attributed to climate change and anthropogenic pressure. The RAMSAR convention of 1971 was among the first initiatives by local and international institutions to conserve wetlands (Betbeder et al., 2013; Gardner \& Davidson, 2011). The conservation efforts have been noted to be increasing over the past two decades.

Wetlands in the Democratic Republic of Congo (DRC) cover approximately $440,000 \mathrm{~km}^{2}$ or $19.2 \%$ of the country's total area and offer habitat to hundred fauna species (Bwangoy et al., 2013). However, they are threatened by degradation, illegal logging, excessive fishing, poaching, the lack of integrated management plans, the weakness of monitoring systems, the delay in implementing the Ramsar vision, and other problems related to the gaps in knowledge and protection of certain aquatic and wetland habitats and their biodiversity (Anon, n.d.). A report published by Orimoloye et al. (2020) indicates that the wetlands' degradation calls for measures to be put in place for assessing and monitoring wetlands.

Reports indicate that $74 \%$ of Lake Edward consists of wetlands. Other significant wetlands in VNP consist of ponds and rivers (Ishasha, Semuliki, Rutshuru and Rwindi), which are habitats for hippopotamuses (Hippopotamus amphibius) (Figure 1). Virunga National Park wetland was enlisted as a Ramsar site of international importance in 1996 based on the following criterion: 1) It constitutes a representative example of a biogeographical region. 2) Several migratory bird species are present. 3) An assemblage of rare, vulnerable, and endangered species (Pillai, 2003). For the two past decades, the VNP wetland faced many challenges, such as poor management of wetland resources where human settlements (fishing villages) located within the National Park boundaries turned the wetland into land for agriculture and pasture (Kujirakwinja, 2010).

Unlike other African mammals, hippopotamuses (Hippopotamus amphibius) are also well-adapted to aquatic life, which makes them unique (Cerling et al., 2008; Timbuka, 2012). Hippopotamuses are among the animal species in Africa threatened by extinction (Lewison \& Oliver, 2008). Hippopotamus populations in most sub-Saharan African countries have decreased by $30 \%$ in the last three decades due to human disturbances (Timbuka, 2012).

In 1974, 30,000 hippos were recorded to be present in Virunga National Park 


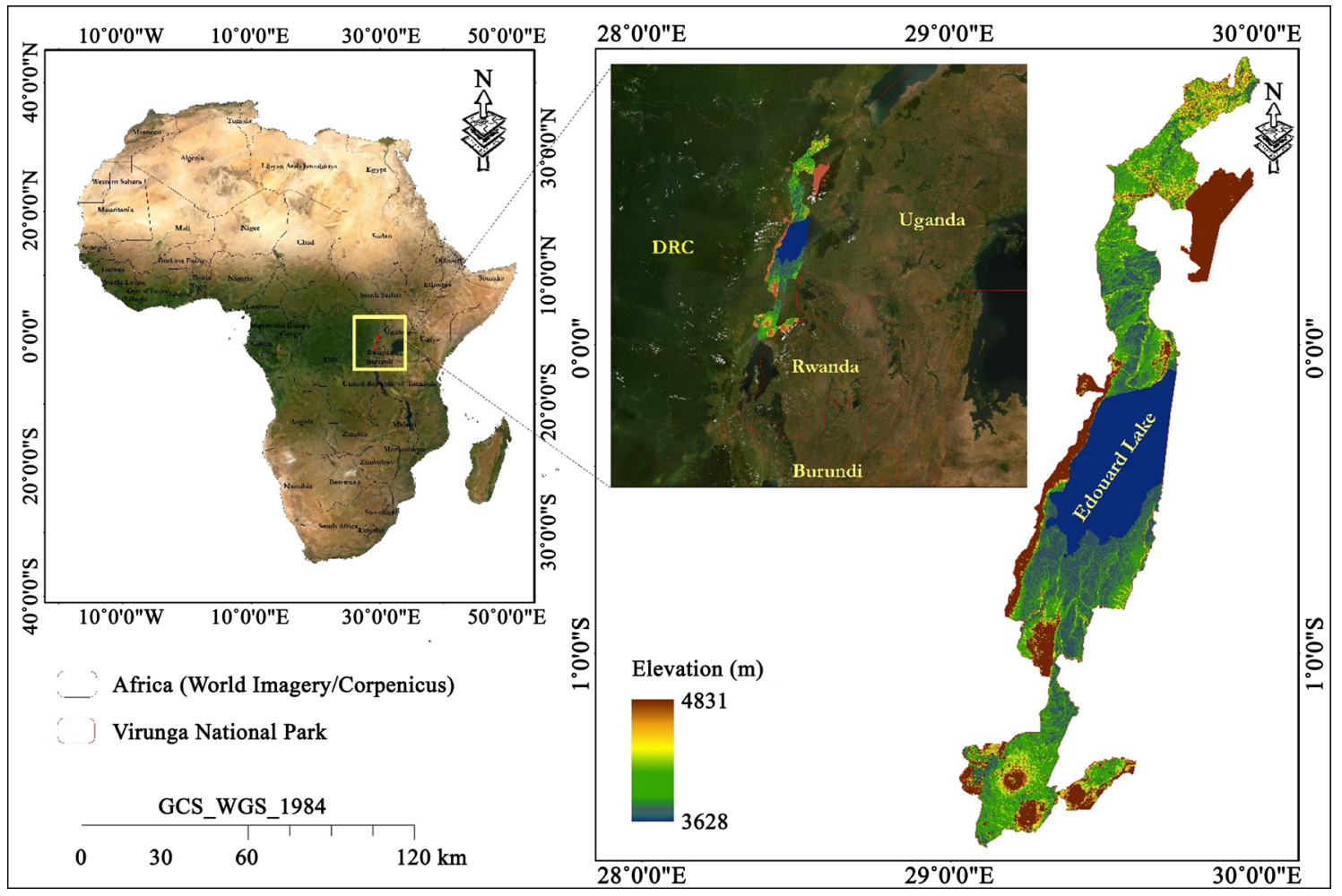

Figure 1. Study area.

wetland, and many of them were found in lake Edward, in areas such as the Rutshuru, Rwindi, Semuliki, and Ishasha Rivers. At the time, VNP was a habitat to the world's largest population of hippos (Languy \& de Merode, 2006; Kujirakwinja, 2010). Unfortunately, for the past two decades, the hippo population has declined by $96 \%$ (Kujirakwinja, 2010).

According to reports published by Adefisan et al. (2015) and Abdelaziz et al. (2018), data obtained from biophysical information and vegetation indices-that is, remote sensing data-are effective for monitoring and assessing temporal patterns of land ecosystems. This has resulted in data sensing data being used in multiple studies to evaluate vital ecosystem features, such as wetland pattern and land surface temperature (Abdelaziz et al., 2018).

Although multiple pieces of research exist regarding the conservation of hippos in VNP, not much is known about the impact of wetland's landscape fragmentation on their population.

This study will answer the following question: Besides poaching, does the wetland fragmentation contribute to the decline of the Hippopotamus population?

This study aims to assess the VNP's landscape fragmentation status and its implication on the decline of the hippos population.

\section{Study Area and Methodology}

\subsection{Study Area}

Virunga National Park initially covered approximately $200 \mathrm{~km}^{2}$ when it was 
proclaimed in 1925, and it is situated in the eastern part of DRC and some sections of the Albertine Rift Valley. Studies published by Languy \& de Merode (2006) indicate that Virunga National Park currently covers $7900 \mathrm{~km}^{2}$, and its size was extended between 1929 and 1950 to protect large animals, such as elephants and buffalos, from the growing number of local communities (Akeley, 1931). In 1979, the United Nations Educational, Scientific and Cultural Organization declared the Virunga National Park a World Heritage Site (WHS). In 1996, the park was listed by Ramsar as one of the major wetlands in the globe. Research published by Languy \& de Merode (2006) indicates that Virunga National Park was listed in 1994 as a WHS whose biodiversity was under significant threat. A wide range of habitats can be found in the park, making it one of Africa's most protected areas rich in diversity. Virunga's National Park diversity can be explained by some of its features such as savannas and lowland forest to its north, Afromontane forest located south of the park, and the alpine habitats on the Rwenzori Mountains (Languy \& de Merode, 2006). The park is rich in biodiversity, evidenced by 196 mammal species, 706 bird species, and 2077 plant species.

\subsection{Methodology}

A research conducted by Groom et al. (2006) indicated that spatial patterns within a landscape could be inferred with the help of remotely sensed imagery. This study's land cover data was obtained using remote sensing techniques with the help of software package ERDAS IMAGINE v16.6 and ArcGIS v10.3. The USGS database was used to obtain free Landsat TM and OLI imageries for 1990, 2005, and 2018. The historical population of hippos and image availability was used as a basis for selecting the yearly images. The images used in the study were geometrically recorded and radiometrically normalized to obtain an appropriate map projection. Our study area's LULC was mapped and classified using the maximum likelihood supervised classification technique. The landscape was classified into seven classes, which included Cropland, Forest, grassland, wetland, scrubland, bare land, and water. Furthermore, accuracy was evaluated, and the KAPPA was $>0.85$, which satisfied the research's objective.

The study used software such as GIS, FRAGSTATS and ERDAS to convert land cover maps into a grid format to facilitate the calculation of landscape metrics at both class and landscape levels. Other calculations performed in the paper entailed ascertaining the combined properties of the patches of a single class or patch style and also determining the combined properties of the whole patch mosaic.

Satellite data (Landsat) was used to evaluate NDVI and NDWI. NIR and red bands are used by NDVI in its formula which is written as:

$$
N D V I=\frac{\rho_{\text {nir }}-\rho_{\text {red }}}{\rho_{\text {nir }}+\rho_{\text {red }}}
$$

Regarding the formula, red denotes the spectral reflectance extents obtained 
in the red and near-infrared sections. As a result, the NDVI ranges from -1.0 to +1.0 . NDWI formula is written as:

$$
N D W I=\frac{X n i r-X s w i r}{X n i r+X s w i r}
$$

Concerning the formula, NIR denotes near-infrared while SWIR refers to the short-wave infrared wavelengths (Gao, 1996).

\subsection{Fragmentation Analysis}

A study published by Wu et al. (2002) indicates that landscape indices have been effective in studying landscape patterns. VNP landscape patterns in the study were analyzed using Fragstats 4.2, which was also used to calculate landscape indices for the respective periods. Landscape fragmentations, shape, and diversity were the selected landscape metrics because they aligned with the study's objectives (Ouyang et al., 2009; Song et al., 2010).

Quantitative information regarding how human activities affect patches was ascertained using landscape fragmentation metrics. The information included things such as, percentage of landscape (PLAND), patch density (PD) and mean patch size (AREA_MN). Information regarding the patches' size and shape can be ascertained using landscape shape metrics, which entails Perimeter-Area Fractal Dimension (PAFRAC) and Land Shape Index (LSI). The evenness of landscapes and their richness can be ascertained using landscape diversity metrics, which capture the structural and compositional components SHDI (Shannon's Diversity Index) and SIDI were selected (Table 1).

Table 1. Selected landscape metrics at class level.

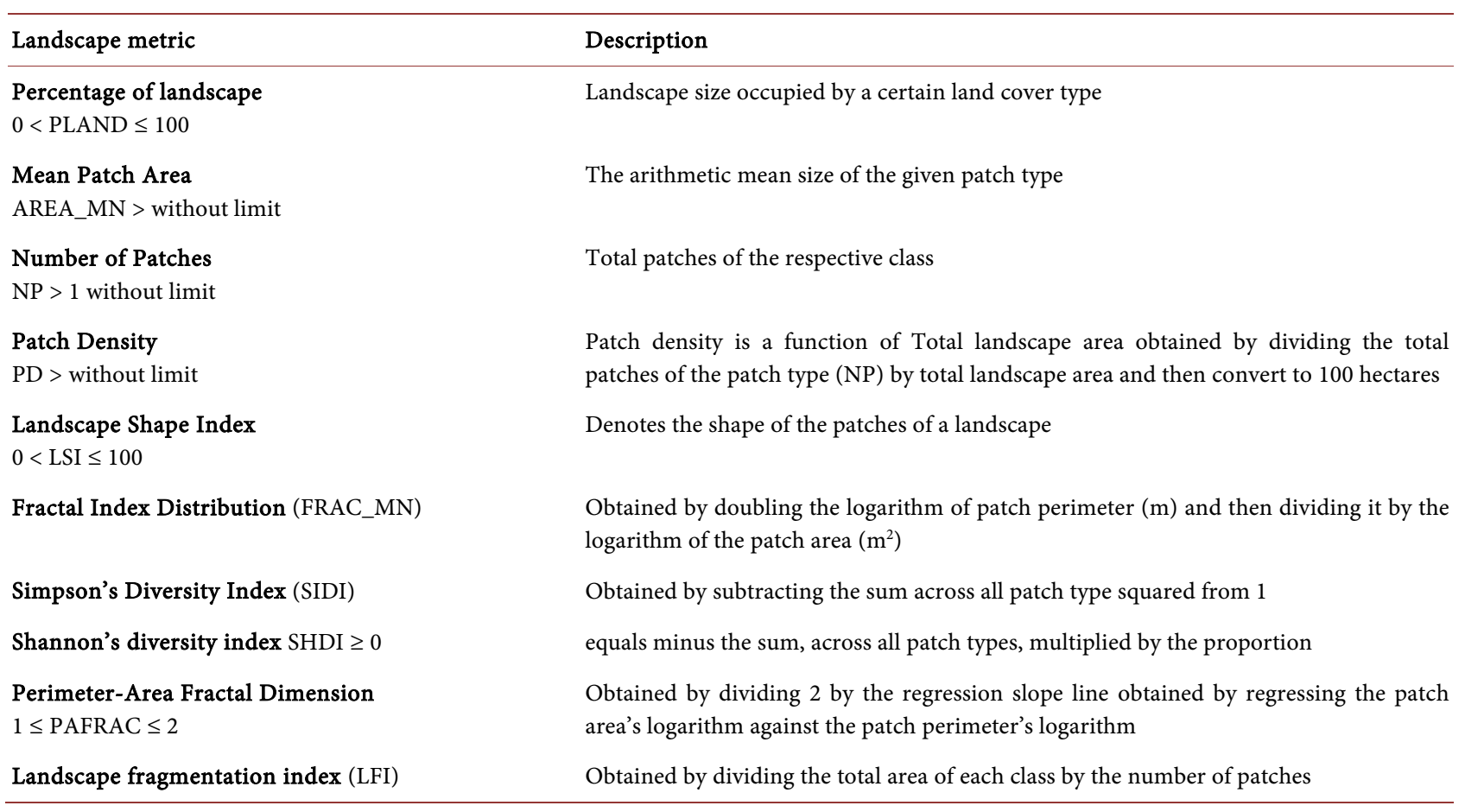


The number of Hippos was found on the IUCN Website https://www.iucn.nl/en/projects/citizen-science-leads-to-better-protection-of-hi ppos-in-dr-congo 1974:30,000 Individuals, 2005:1000, 2015-2018:2500 individuals.

\section{Results and Discussion}

\subsection{Spatial Distribution of NDVI and NDWI between 1990 and 2018}

Our study utilized spatial science in assessing Virunga National Park's wetland spatiotemporal change for the period between 1990 and 2018. The spatial model of vegetation and water index for the period of the study is displayed in Figures 2-5. The status of the vegetation and water in the study was assessed using
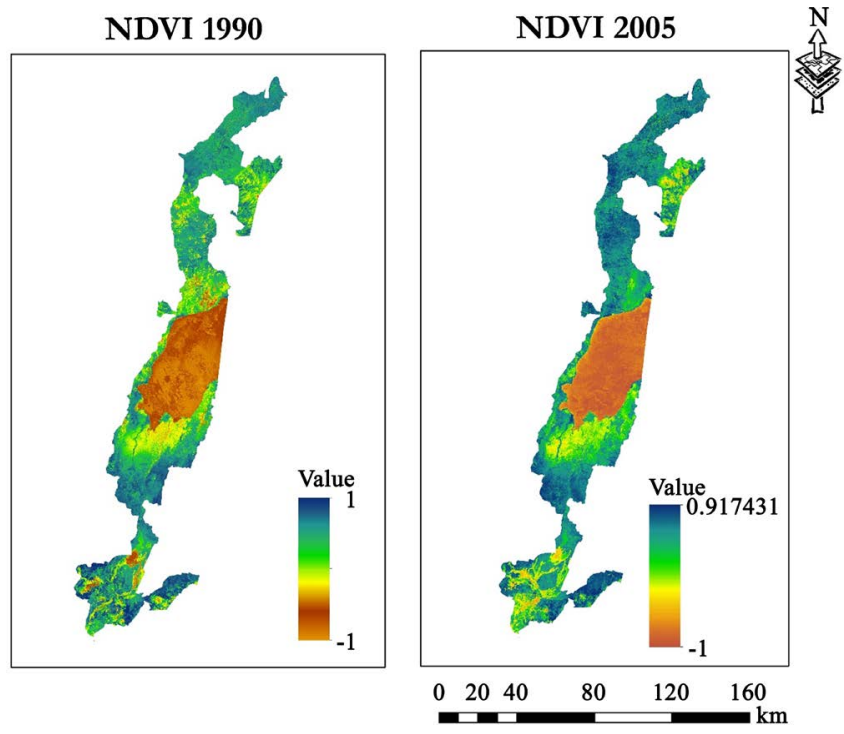

Figure 2. NDVI for the period 1990 and 2005.
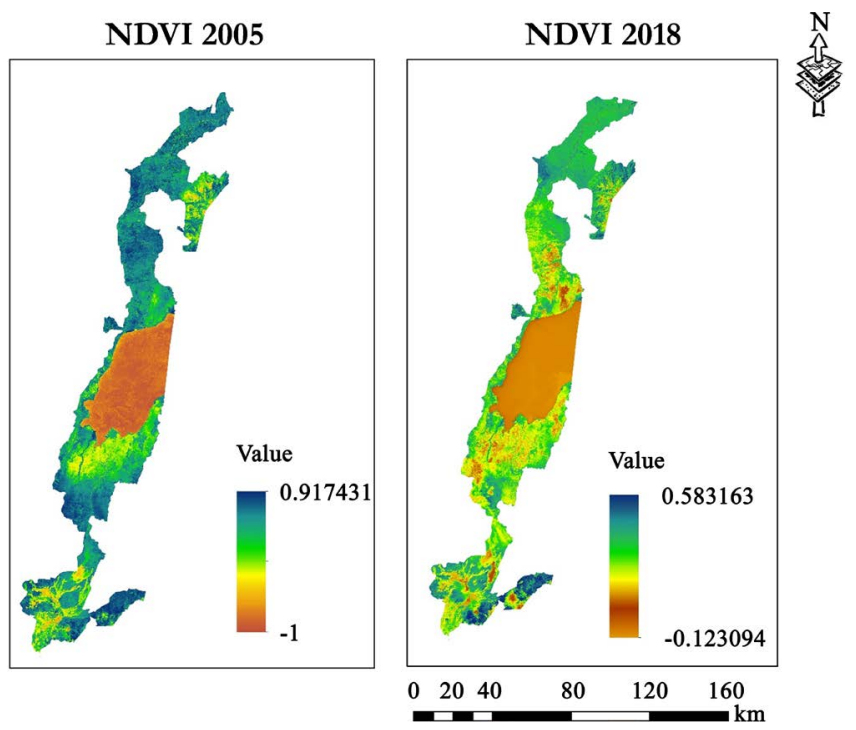

Figure 3. NDVI for the period 2005 and 2018. 


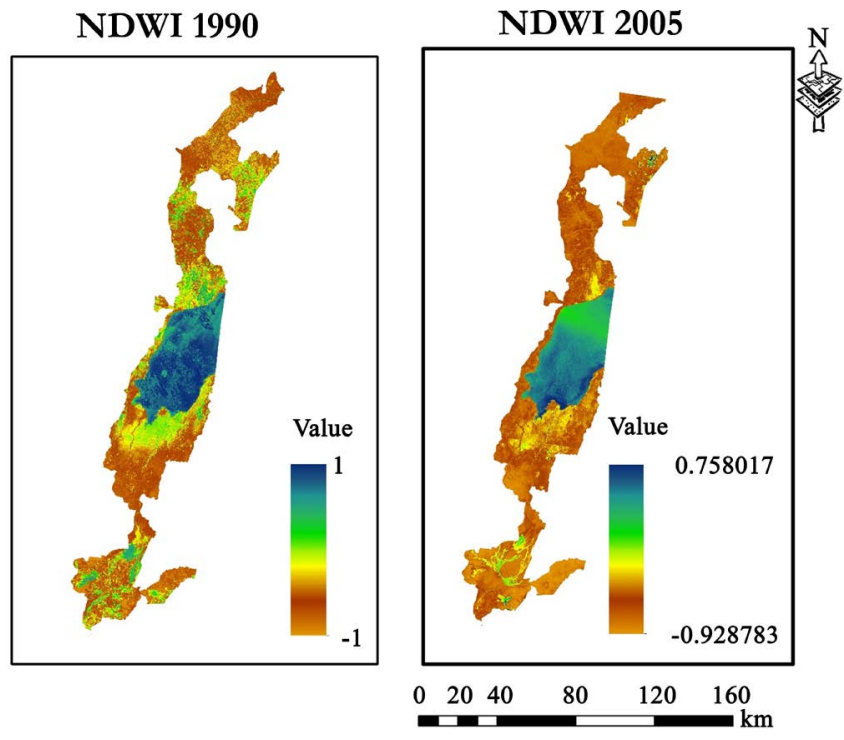

Figure 4. NDWI for the period 1990 and 2005.

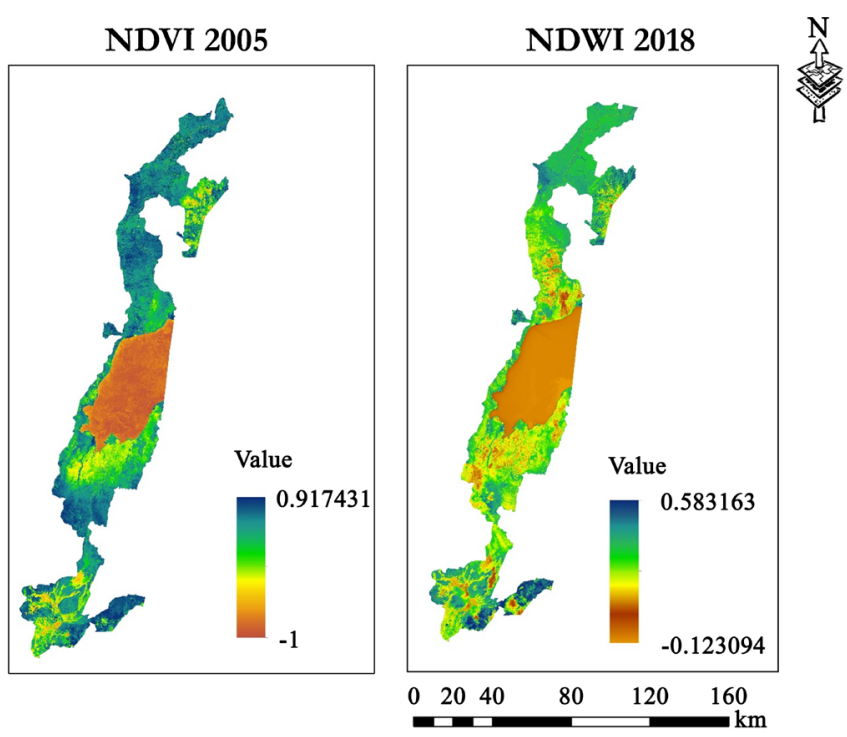

Figure 5. NDWI for the period 2005 and 2018.

NDVI and NDWI. The obtained results ran parallel to that of the study conducted by Orimoloye et al. (2019), which stated that wetland depletion was observed in zones with low NDWI while slight or no shrinkage of wetland was observed in areas with high NDWI (Figure 5). The NDVI pattern of Virunga National Park is displayed in Figure 2 and Figure 3 for the period covered by the study. The study's results showed the spatial and temporal change of Virunga National Park wetland landscapes for approximately thirty years. The extent of wetland cover in the Virunga National Part was obtained by calculating the NDVI for each year. The study also revealed that the water index and the phenology of wetland dynamics were one of the reasons for the change in vegetation in the region. The obtained results also showed a correlation between climate change and the vegetation changes, which confirmed the results obtained by 
studies conducted by Petus et al. (2013) and Lee \& Yeh (2009).

\subsection{Spatial Pattern of Change in Landscape and Wetlands Shift in VNP between 1990 and 2018}

The first step in the study after classifying each image and land cover for the research period was to measure each land cover class extension over the total area, as shown in Table 2. Regarding the study area, the forest was observed to be the dominant land cover, followed by water, cropland, grassland, bare land, shrubland, and wetland. During the period from 1990 to 2018, forest decreased from $39.8 \%$ to $38.6 \%$; grassland declined from $11.3 \%$ to $11.1 \%$, shrubland declined from $0.73 \%$ to $0.7 \%$, and water from 22.6 to 21.4 , while cropland and bare land increased from $22.5 \%$ to $24 \%$ and $2.8 \%$ to $3.75 \%$, respectively. The decrease in forest and grassland was due to increased illegal charcoal production and substance agriculture within the VNP boundaries (Crawford \& Bernstein, 2008).

For the wetland class, the highest decrease was found for the period 1990-2005 due to uncontrolled human activities within the park during the civil war in DRC (1996-2004) and the increase of population in the 14 fishing villages within the park (Philippe et al., 2019). At this period in 2005, the population of Hippos was 1000, a significant drop from 10,000 in 1990

(https://www.iucn.nl/en/projects/citizen-science-leads-to-better-protection-of-hi ppos-in-dr-congo).

\subsection{Class-Level Landscape Indicators}

The source for calculating landscape metrics at the class level was the land cover maps using FRAGSTATS software (Wu et al., 2002). The landscape metrics done at the class level regarding our study are depicted in Table 1 . The dynamics of the landscape structure and ecosystem dynamics will be understood and described better by analyzing many landscape metrics instead of just one.

Forest is the dominant land cover in our study area, and the results show a decline of forest in terms of PLAND (percentages of landscape from 39.9 to

Table 2. Land use land cover areas in the study area per classes, 1990 and 2018.

\begin{tabular}{|c|c|c|c|c|c|c|c|c|}
\hline \multicolumn{3}{|c|}{ Area in 1990} & \multicolumn{3}{|c|}{ Area in 2005} & \multicolumn{3}{|c|}{ Area in 2018} \\
\hline Class & $\mathrm{km}^{2}$ & $\%$ & Class & $\mathrm{km}^{2}$ & $\%$ & Class & $\mathrm{km}^{2}$ & $\%$ \\
\hline Cropland & 1663.74 & 22.5 & Cropland & 1751 & 23.6 & Cropland & 1591 & 24 \\
\hline Forest & 2953.08 & 39.8 & Forest & 2899 & 39.1 & Forest & 858 & 38.6 \\
\hline Grassland & 836.91 & 11.3 & Grassland & 835 & 11.2 & Grassland & 826 & 11.1 \\
\hline Wetland & 13.23 & 0.18 & Wetland & 11 & 0.14 & Wetland & 12 & 0.16 \\
\hline Shrubland & 54.36 & 0.73 & Shrubland & 52 & 0.70 & Shrubland & 55 & 0.70 \\
\hline Bare area & 205.74 & 2.8 & Bare land & 221 & 2.9 & Bare area & 278 & 3.75 \\
\hline Water & 1674.45 & 22.6 & Water & 1633 & 22 & Water & 1591 & 21.4 \\
\hline Total & \multicolumn{2}{|c|}{$100 \%$} & Total & \multicolumn{2}{|c|}{$100 \%$} & Total & \multicolumn{2}{|c|}{$100 \%$} \\
\hline
\end{tabular}


38.6), the NP (number of patches) augmented from 338 to 344, and PD (patch density) increased from 0.432 to 0.44 . The mean patch area (AREA_MN) decreased from 923.4 to 877.9 during the period from 1990 to 2018 . In this sense, the forest fragmentation increased during the period of the study. On the other hand, the LSI (landscape Shape Index) decreased from 24.5 to 23.9, the FRAC_MN and the PAFRAC did not change. The NP (Number of Patches) increased for the shrubland, grassland, and Bare area, which shows that the three classes were highly fragmented. The SHDI and SIDI at the landscape level showed a slight change from 1.43 in 1990 to 1.45 in 2018 and from 0.72 to 0.73 respectively.

For the wetland class, which is our target class, as it is the habitat of hippos, the results revealed the decrease in terms of PLAND and LSI for the first decade and increased for the next decade. For the period 1990-2005, PLAND decreased from 0.1798 to 0.1453 and increased from 0.1453 to 0.1811 for 2004-2018. LSI declined from 7.28 to 7.16 for the first decade and rose from 7.16 to 7.56 for the next decade (Table 3 ). During the whole period of our study, the NP increased from 36 to 38 for the first period and from 38 to 42 for the second period (Table 3). The LFI at the wetland level increased from 2.7 in 1990 to 3.45 in 2005 and 3.5 in 2018 ('Table 4). These values indicate that the VNP's wetland has fragmented for the period of our study 1990_2018. VNP's wetland size and shape

Table 3. Class level's landscape metrics, 1990, 2005 and 2018.

\begin{tabular}{|c|c|c|c|c|}
\hline & & 1992 & 2005 & 2015 \\
\hline \multirow{7}{*}{ Cropland } & PLAND & 22.4689 & 23.6468 & 24.0676 \\
\hline & NP & 379 & 357 & 348 \\
\hline & $\mathrm{PD}$ & 0.0485 & 0.0457 & 0.0445 \\
\hline & LSI & 28.4189 & 26.906 & 26.7728 \\
\hline & AREA_MN & 463.591 & 517.959 & 540.811 \\
\hline & FRAC_MN & 1.0453 & 1.0457 & 1.0461 \\
\hline & PAFRAC & 1.4626 & 1.4672 & 1.4716 \\
\hline \multirow{7}{*}{ Forest } & PLAND & 39.9135 & 39.18 & 38.6218 \\
\hline & NP & 338 & 320 & 344 \\
\hline & $\mathrm{PD}$ & 0.0432 & 0.0409 & 0.044 \\
\hline & LSI & 24.5899 & 23.9414 & 23.9701 \\
\hline & AREA_MN & 923.411 & 957.429 & 877.943 \\
\hline & FRAC_MN & 1.0451 & 1.0481 & 1.0467 \\
\hline & PAFRAC & 1.4694 & 1.4788 & 1.4812 \\
\hline \multirow{4}{*}{ Shrubland } & PLAND & 0.7342 & 0.6999 & 0.7423 \\
\hline & NP & 104 & 111 & 117 \\
\hline & $\mathrm{PD}$ & 0.0133 & 0.0142 & 0.015 \\
\hline & LSI & 12.4057 & 13.0041 & 13.6048 \\
\hline
\end{tabular}




\section{Continued}

\begin{tabular}{|c|c|c|c|c|}
\hline & AREA_MN & 55.2068 & 49.3097 & 49.6113 \\
\hline & FRAC_MN & 1.0365 & 1.0361 & 1.0376 \\
\hline & PAFRAC & 1.4843 & 1.5238 & 1.5267 \\
\hline \multirow{7}{*}{ Wetland } & PLAND & 0.1798 & 0.1453 & 0.1811 \\
\hline & NP & 36 & 38 & 42 \\
\hline & $\mathrm{PD}$ & 0.0046 & 0.0048 & 0.0048 \\
\hline & LSI & 7.2828 & 7.1636 & 7.5584 \\
\hline & AREA_MN & 39.0457 & 39.05 & 39.3732 \\
\hline & FRAC_MN & 1.0311 & 1.0352 & 1.0391 \\
\hline & PAFRAC & 1.4804 & 1.5751 & 1.6743 \\
\hline \multirow{7}{*}{ Grassland } & PLAND & 11.3012 & 11.2749 & 11.1489 \\
\hline & NP & 146 & 150 & 163 \\
\hline & $\mathrm{PD}$ & 0.0187 & 0.0192 & 0.0208 \\
\hline & LSI & 16.3673 & 16.5246 & 17.0365 \\
\hline & AREA_MN & 605.289 & 587.779 & 534.857 \\
\hline & FRAC_MN & 1.0442 & 1.0436 & 1.0416 \\
\hline & PAFRAC & 1.4512 & 1.4572 & 1.4683 \\
\hline \multirow{7}{*}{ Bare land } & PLAND & 2.776 & 2.9873 & 3.7548 \\
\hline & NP & 39 & 38 & 62 \\
\hline & $\mathrm{PD}$ & 0.005 & 0.0049 & 0.0079 \\
\hline & LSI & 10.667 & 10.662 & 11.487 \\
\hline & AREA_MN & 556.595 & 614.736 & 473.568 \\
\hline & FRAC_MN & 1.0451 & 1.0426 & 1.0392 \\
\hline & PAFRAC & 1.4752 & 1.497 & 1.4766 \\
\hline \multirow{7}{*}{ Water } & PLAND & 22.6265 & 22.0658 & 21.5035 \\
\hline & NP & 35 & 34 & 33 \\
\hline & $\mathrm{PD}$ & 0.0045 & 0.0043 & 0.0017 \\
\hline & LSI & 3.3834 & 2.803 & 1.9734 \\
\hline & AREA_MN & 505.524 & 507.497 & 1293.48 \\
\hline & FRAC_MN & 1.0339 & 1.0233 & 1.031 \\
\hline & PAFRAC & 1.2164 & 1.1696 & 1.1368 \\
\hline
\end{tabular}

Table 4. Correlation between landscape Fragmentation and Hippos population.

\begin{tabular}{ccc}
\hline Year & LFI & Number of Hippos \\
\hline 1990 & 2.721088 & 10000 \\
2005 & 3.454545 & 1000 \\
2018 & 3.5 & 2500 \\
\hline
\end{tabular}


remained stable for the period of our study, as indicated by the values of AREA_MN and FRAC_MN and the slight increase of PAFRAC.

\subsection{Hippos Habitats Fragmentation}

In VNP, Hippos are found mainly in the lake Edward, Rwindi, Rutshuru, Semuliki, and Ishasha Rivers (Kujirakwinja, 2010). In the 1970s, VNP was the world's largest hippo habitat with a population of 30,000 (Delvingt, 1978; Languy et al., 1994). For the following decades, hippos declined dramatically by $96 \%$ from 30,000 in 1974 to 10,000 in 1990 and finally to 1000 in 2005 . The number increased again from 2015 to 2018 to 2500

(https://www.iucn.nl/en/projects/citizen-science-leads-to-better-protection-of-hi ppos-in-dr-congo).

The decline of hippos in Virunga National Park can be attributed to bushmeat trade and poaching for food, which according to Languy et al. (1994) and Plumptre et al. (2008), is due to the presence of 14 fishing villages in the park that. The rationale for this is that the individuals living in the fishing villages have converted parts of the park into land for agriculture and human settlement, which has affected hippos' distribution due to land fragmentation and degradation (Crawford \& Bernstein, 2008).

\subsection{Correlation between Hippos Population and Landscape Fragmentation}

LFI informs the degree of landscape interference in terms of fragmentation. From 1990 to 2018, findings showed that the LFIs increased from 2.7 to 3.5, a growth rate of $28.6 \%$. At the wetland level, the overall observation (Table 4 and Figure 6) depicted a strong negative correlation between the number of hippos and LFI values since the number of hippos was decreasing with the increment in LFIs.

\section{Conclusion}

Remote sensing data was invaluable in providing an accurate representation of

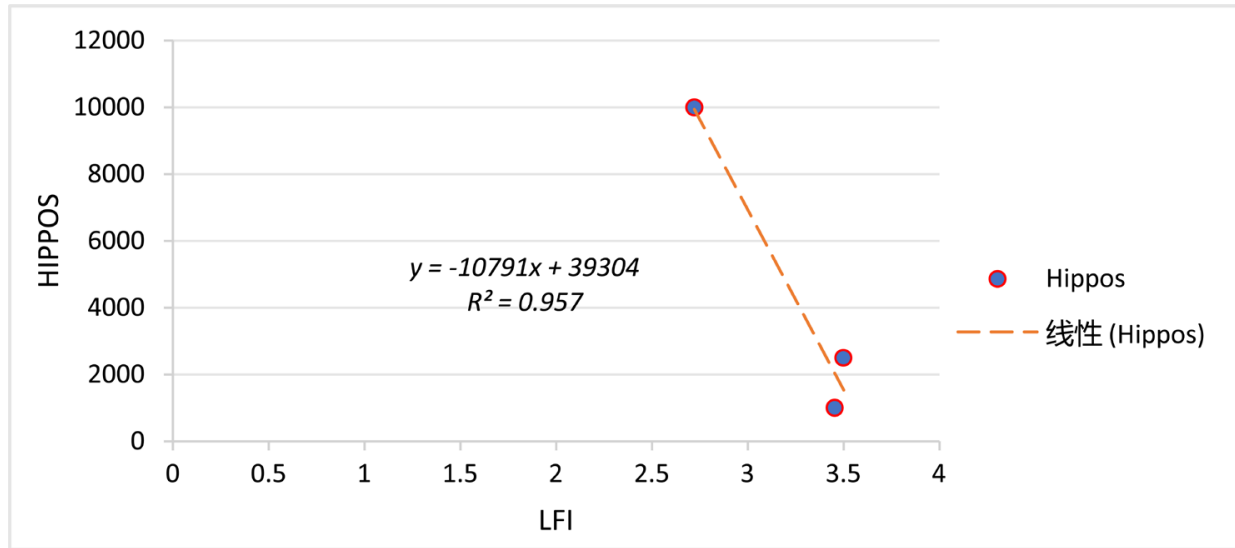

Figure 6. The correlation between the wetland fragmentation and Hippos population. 
the study area's land cover dynamics. The study results showed that vegetation cover has significantly reduced in the study area while cropland has increased (Table 2). The wetland, which is the habitat of Hippos, also decreased, especially for the period 1990-2005 (Table 2). This result answered the research question as it showed that not only poaching contributed to the decline of Hippos population in the VNP, but also the landscape fragmentation did.

The study results similarly revealed that the NDVI and NDWI significantly declined in 2018 compared to previous years. According to the study's findings, the most significant decrease in NDWI and NDVI was witnessed in 2018. This could be the primary reason for the reduced size of wetland in the study area during 28 years, as the spatial trend of vegetation decreased with NDVI closed to -1 . The results show that the wetland in the region was replaced by pasture and cropland. This implies that the study area's ecosystem and wetland animals will be negatively affected if the wetland shift continues.

According to the study's results, wetland's state and its effect on the environment and biodiversity can be identified by co-joining the land feature classification with the NDWI and NDVI. The results also revealed that the extent of wetland shrinkage was more evident for the first period (1990-2005) than in the next decade (2005-2018).

Analysis of the landscape metrics revealed that forest occupied the most significant portion of the study area, followed by water, cropland, grassland, bare land scrubland, and wetland. During the study period, cropland and bare land were observed to increase while forest, grassland, scrubland, and wetland decreased. The change dynamics revealed decreased fragmentation of the forested landscape. The study results also showed that forested landscape and wetlands have become fragmented during the last two decades. Also, according to the obtained results, a significant correlation exists between the number of hippos and wetlands. The results of this study will assist as a starting point in the conservation management of National Park, especially in VNP and will also help to reduce the effects of wetland fragmentation on aquatic life.

\section{Acknowledgements}

The authors express their gratitude to the United State Geological Survey (USGS) for providing available satellite imagery of satellite imagery, the research sponsor, which is a sub-project of the China National Key Research and Development Project (No. 2016YFC0503306). The University Chinese Academy of Sciences scholarship. The author is thankful to the Xinjiang Institute of Ecology and Geography for providing the good research environment and to Professor Yang Zhaoping for supervising this work.

\section{Conflicts of Interest}

The authors declare no conflicts of interest regarding the publication of this paper. 


\section{References}

Abdelaziz, R., El-Rahman, Y. A., \& Wilhelm, S. (2018). Landsat-8 Data for Chromite Prospecting in the Logar Massif, Afghanistan. Heliyon, 4, e00542.

https://doi.org/10.1016/j.heliyon.2018.e00542

Adefisan, E. A., Bayo, A. S., \& Ropo, O. I. (2015). Application of Geo-Spatial Technology in Identifying Areas Vulnerable to Flooding in Ibadan Metropolis. Journal of Environment and Earth Science, 5, 153-166.

Akeley, M. L. J. (1931). National Parks in Africa: The Extension of Wildlife Conservation. Science, 74, 584-588. https://doi.org/10.1126/science.74.1928.584

Anon (n.d.). DRC Wetlands Governance and Management Profile Developed by Nile Basin Initiative.

Assessment, Millennium Ecosystem (2005). Ecosystems and Human Well-Being: Wetlands and Water. Washington DC: World Resources Institute.

Betbeder, J., Gond, V., Frappart, F., Baghdadi, N. N., Briant, G., \& Bartholomé, E. (2013). Mapping of Central Africa Forested Wetlands Using Remote Sensing. IEEE Journal of Selected Topics in Applied Earth Observations and Remote Sensing, 7, 531-542.

Blankespoor, B., Dasgupta, S., \& Laplante, B. (2014). Sea-Level Rise and Coastal Wetlands. Ambio, 43, 996-1005. https://doi.org/10.1007/s13280-014-0500-4

Bwangoy, J.-R. B., Hansen, M. C., Potapov, P., Turubanova, S., \& Lumbuenamo, R. S. (2013). Identifying Nascent Wetland Forest Conversion in the Democratic Republic of the Congo. Wetlands Ecology and Management, 21, 29-43. https://doi.org/10.1007/s11273-012-9277-Z

Cerling, T. E., Harris, J. M., Hart, J. A., Kaleme, P., Klingel, H., Leakey, M. G., Levin, N. E., Lewison, R. L., \& Passey, B. H. (2008). Stable Isotope Ecology of the Common Hippopotamus. Journal of Zoology, 276, 204-212. https://doi.org/10.1111/j.1469-7998.2008.00450.x

Crawford, A., \& Bernstein, J. (2008). MEAs, Conservation and Conflict: A Case Study of Virunga National Park, DRC. Winnipeg: International Institute for Sustainable Development.

Delvingt, W. (1978). Écologie de l'hippopotame (Hippopotamus amphibius L.) Au Parc National Des Virunga (Zaïre).

Gao, B.-C. (1996). NDWI-A Normalized Difference Water Index for Remote Sensing of Vegetation Liquid Water from Space. Remote Sensing of Environment, 58, 257-266. https://doi.org/10.1016/S0034-4257(96)00067-3

Gardner, R. C., \& Davidson, N. C. (2011). The Ramsar Convention. In Wetlands (pp. 189203). Berlin: Springer. https://doi.org/10.1007/978-94-007-0551-7 11

Groom, G., Mücher, C. A., Ihse, M., \& Wrbka, T. (2006). Remote Sensing in Landscape Ecology: Experiences and Perspectives in a European Context. Landscape Ecology, 21, 391408. https://doi.org/10.1007/s10980-004-4212-1

Kujirakwinja, D. (2010). The Status and Conservation of Common Hippopotamuses in Virunga National Park.

Languy, M., \& de Merode, E. (2006). A Brief Overview of Virunga National Park. In Virunga: The Survival of Africa's First National Park (pp. 21-64). Tielt: Lannoo.

Languy, M., Smith, F., \& Nicholas, A. (1994). Recensement Des Hippopotames Communs Hippopotamus Amphibius Dans Le Parc National Des Virunga. WWF Report, Goma, Zaïre.

Lee, T.-M., \& Yeh, H.-C. (2009). Applying Remote Sensing Techniques to Monitor Shift- 
ing Wetland Vegetation: A Case Study of Danshui River Estuary Mangrove Communities, Taiwan. Ecological Engineering, 35, 487-496. https://doi.org/10.1016/j.ecoleng.2008.01.007

Lewison, R., \& Oliver, W. (2008). Hippopotamus Amphibius. The IUCN Red List of Threatened Species 2014.

Orimoloye, I. R., Kalumba, A. M., Mazinyo, S. P., \& Nel, W. (2020). Geospatial Analysis of Wetland Dynamics: Wetland Depletion and Biodiversity Conservation of Isimangaliso Wetland, South Africa. Journal of King Saud University_Science, 32, 90-96. https://doi.org/10.1016/j.jksus.2018.03.004

Orimoloye, I. R., Mazinyo, S. P., Kalumba, A. M., Nel, W., Adigun, A. I., \& Ololade, O. O. (2019). Wetland Shift Monitoring Using Remote Sensing and GIS Techniques: Landscape Dynamics and Its Implications on Isimangaliso Wetland Park, South Africa. Earth Science Informatics, 12, 553-563. https://doi.org/10.1007/s12145-019-00400-4

Ouyang, W., Skidmore, A. K., Hao, F. H., Toxopeus, A. G., \& Abkar, A. (2009). Accumulated Effects on Landscape Pattern by Hydroelectric Cascade Exploitation in the Yellow River Basin from 1977 to 2006. Landscape and Urban Planning, 93, 163-171. https://doi.org/10.1016/j.landurbplan.2009.07.001

Petus, C., Lewis, M., \& White, D. (2013). Monitoring Temporal Dynamics of Great Artesian Basin Wetland Vegetation, Australia, Using MODIS NDVI. Ecological Indicators, 34, 41-52. https://doi.org/10.1016/j.ecolind.2013.04.009

Philippe, M. T., Malengera, K., \& Karume, K. (2019). Key Factors Driving Deforestation in North-Kivu Province, Eastern DR-Congo Using GIS and Remote Sensing. American Journal of Geographic Information System, 8, 11-25.

Pillai, S. (2003). Information Sheet on Ramsar Wetlands (pp. 1-8). Solent. Ramsar, 7 (1990).

Plumptre, A. J., Kujirakwinja, D., Owiunji, I., Rwetsiba, A., Wanyama, F., \& Mwima, P. (2008). Strengthening Elephant Conservation in the Greater Virunga Landscape. Final Report for USFWS Project 98210-16.

Song, K. Y., Zhao, J. Y., Ouyang, W., Zhang, X., \& Hao, F. H. (2010). LUCC and Landscape Pattern Variation of Wetlands in Warm-Rainy Southern China over Two Decades. Procedia Environmental Sciences, 2, 1296-1306.

https://doi.org/10.1016/j.proenv.2010.10.140

Timbuka, C. (2012). The Ecology and Behaviour of the Common Hippopotamus, Hippopotamus amphibious L. in Katavi National Park, Tanzania: Responses to Varying Water Resources.

Wu, J. G., Shen, W. J., Sun, W. Z., \& Tueller, P. T. (2002). Empirical Patterns of the Effects of Changing Scale on Landscape Metrics. Landscape Ecology, 17, 761-782.

https://doi.org/10.1023/A:1022995922992 